ORIGINAL ARTICLE

\title{
Neonatal research: the parental perspective
}

\author{
B J Stenson, J-C Becher, N Mclntosh
}

Arch Dis Child Fetal Neonatal Ed 2004;89:F321-F324. doi: 10.1136/adc.2002.021931

\begin{abstract}
Objectives: To investigate the recollections of parents consenting for their infants to be research subjects and determine their views about the need for consent.

Subjects: Parents of 154 sick newborn infants enrolled in a randomised trial in the early neonatal period. All parents had given written consent and received printed information. Methods: A questionnaire and accompanying letter was sent to the parental home 18 months later. Nonresponders were sent a further questionnaire and letter.

Results: Response rate was 64\% (99/154). Some respondents (12\%) did not remember being asked to consent to their baby joining a study, and a further $6 \%$ were unsure. Most of the respondents $(79 \%)$ were happy, 13\% neutral, and $8 \%$ unhappy with their decision to give consent. None felt heavy pressure to agree. Entering the trial caused $24 \%$ of respondents to feel more anxious, $56 \%$ neutral, and $20 \%$ less anxious about their baby. Most of the respondents (83\%) would be unhappy to forgo the consent process for trials passed by the institutional ethics committee.

Conclusions: A significant proportion of parents who give written consent for a trial in the early neonatal period do not later remember having done so. Parents who have had experience of neonatal research would be unhappy for their baby to be enrolled in a study that had ethics committee approval without their consent being obtained.
\end{abstract}

See end of article for

authors' affiliations

Correspondence to: Dr Stenson, Neonatal Unit, Simpson Centre for Reproductive Health, Royal Infirmary, Little France, Edinburgh EH16 4SU, Scotland, UK; ben. stenson@luht.scot.nhs.uk

Accepted 27 July 2003

W ritten consent from someone with parental responsibility is generally required before any child is enrolled in a clinical trial. Although it may safeguard the child's best interests, it is associated with many difficulties. Concern is expressed about the additional stress placed on parents. ${ }^{1}$ The ability of parents to process information and make informed decisions under these circumstances is questioned. ${ }^{2}$ Alternatives to the consent process have been proposed, ${ }^{3}{ }^{4}$ but these may be unacceptable to the parents whose consent would otherwise be sought. ${ }^{5}$ Serious concerns about the integrity of the consent process may be raised later, based on individual recollections. ${ }^{67}$ There are few data on the experiences of real parents who have been approached for consent. Snowdon et $a l^{8}$ interviewed the parents of 21 infants who were enrolled in the ECMO trial. ${ }^{9}$ They found that some were unsure whether their babies were in a trial or not. In the Euricon study, ${ }^{10}$ five of 200 parents could not remember being asked to give consent for a trial. We aimed to determine from parents whether they remembered being asked to give consent for a research study and how they felt the research had affected their experience as parents of a sick infant.

\section{PATIENTS AND METHODS}

The subjects were the parents of 199 infants entered into a randomised controlled trial of pulmonary function testing which was conducted in the Simpson Memorial Maternity Pavilion, Edinburgh between August 1991 and June 1993. ${ }^{11}$ In all cases the parents were given a printed information sheet and a detailed verbal description of the trial by a single individual (BS). Whenever possible, both parents were seen. Infants were enrolled on the first day that they required mechanical ventilation, and regular measurements of respiratory system compliance were made as long as they remained ventilated. The intervention group had the test results supplied to their clinicians with accompanying interpretation and standardised clinical management advice.

Control infants were managed without the test results or the advice. Outcome measures included the incidence of death, chronic lung disease, pneumothorax, and intraventricular haemorrhage. No adverse events were attributed to the trial.

Several other studies were taking place in the unit at the time, including randomised trials of alternative surfactant regimens and a randomised controlled trial of morphine in ventilated infants. Some infants joined more than one study. The pulmonary function testing trial was chosen to provide the cohort for this questionnaire study because it enrolled more babies than the others.

A short questionnaire was constructed using Likert scales and closed and open questions. This sought to determine from the parents $(a)$ whether they remembered signing a consent form and receiving an information sheet, $(b)$ their perceptions of the adequacy and accuracy of information given and their understanding of that information, (c) whether they felt under pressure to consent and whether they knew that they could reverse their decision at any time, $(d)$ the effect of the process on their anxiety levels, and (e) their overall satisfaction looking back on the episode. The questionnaire also assessed sociodemographic factors. It was piloted on 25 parents recently approached for study consent to check its face validity and comprehensibility before the final version was drafted. A copy of the questionnaire can be supplied by the authors on request. With the assistance of the Stillbirth and Neonatal Death Society (SANDS), the questionnaire and accompanying letter were reviewed by bereaved parents, some of who had participated in neonatal research.

Eighteen months after the trial finished, the questionnaire and a letter of explanation were sent with a reply paid envelope to the parents of all infants who were traced.

No indication was given in the letter whether or not the infant had participated in research, nor were the parents asked to respond in relation to any specific study. Parents of twins and triplets were sent a single questionnaire. If no reply was received, a second copy of the questionnaire and letter were sent but no further effort was made to contact the parents. Consent to the questionnaire study was not obtained as the parents could choose whether or not to complete it. 
Both the original trial and the questionnaire study were approved by the institutional ethics committee.

The results are presented as the percentage of respondents who gave a particular answer, with a sensitivity analysis in parentheses that gives the range of responses if it is assumed that all non-responders agreed strongly or disagreed strongly with each question.

\section{RESULTS}

The pulmonary function testing trial enrolled 199 infants. This included 11 twin pairs and two sets of triplets. Of the 184 families, 30 had no traceable forwarding address. Questionnaires were sent to the remaining 154 families, and 99 replies (64\%) were received. The infants of responding and non-responding parents were similar in study group assignment in the original trial. Consent for the original trial was refused on two occasions. The identity of these parents was not recorded. Twelve replies came from single mothers, 12 from unmarried couples, and 75 from married couples. Mothers alone completed 57 questionnaires, fathers alone four, and both parents together 38 .

Of the 99 respondents, $12 \%(8-44 \%)$ could not remember being approached for consent and did not think that their infant had participated in a study.

These 12 respondents were evenly distributed across the original trial with no bias attributable to the length of time between original recruitment and receipt of the questionnaire. A further 6\% (4-40\%) remembered being approached for consent but were unsure whether their infant participated in a study. Overall, 62\% (34-79\%) felt completely happy, $17 \%$ reasonably happy, 13\% neutral, 5\% slightly unhappy, and $3 \%(2-46 \%)$ very unhappy with their decision. The $3 \%$ that were very unhappy did not give the reasons. Most (91\% $(50-94 \%))$ remembered that they were free to change their minds at any time. The information sheet on the original study was remembered by $70 \%(40-83 \%)$ and was kept by $21 \%(12-55 \%)$.

None of the respondents felt that they were placed under a lot of pressure to consent, $26 \%(14-58 \%)$ felt a little pressure, and $74 \%(42-86 \%)$ felt no pressure. A quarter $(24 \%$ $(13-58 \%))$ felt that the study increased their anxiety, $20 \%$ (11-56\%) felt less anxious, and 56\% (31-76\%) felt that it made no difference. Of those that remembered being approached, $89 \%(50-95 \%)$ felt that a full explanation of the studies was given. The explanation was felt to have been understood completely by $27 \%$ (15-60\%), reasonably well by $42 \%(23-68 \%)$, a little by $27 \%(15-60 \%)$, and not at all by $4 \%$ $(2-47 \%)$ of respondents. It was felt by $87 \%(49-94 \%)$ that being in a study would not affect the general level of care given to their baby, and $12 \%(6-51 \%)$ even thought that their baby may get better care. A question asking the parents to describe what the research study was about was answered by 59 respondents. Answers were too brief to measure the level of understanding that the parents had, and a number of different studies were described.

The last question was: "Before we start any research study an independent committee made up of doctors and the general public (the ethics committee) has to agree that it is safe and worthwhile. Now that you know that, how would you feel about us being allowed to include your baby in a study without having to ask your permission as long as the ethics committee had passed it as safe?". The response was that $60 \%(38-75 \%)$ would be very unhappy and $23 \%$ (15-51\%) a little unhappy.

Of the 99 respondents, 39\% were college educated and they were significantly more likely to have felt a little pressure to agree to enter the study than non-college educated respondents (33\% $\vee 19 \% ; \chi^{2}$ test, $\left.\mathrm{p}<0.05\right)$. Otherwise the responses of these two subgroups were similar.
Of the 154 families who were traced, 20 infants had died in hospital. Questionnaires were returned by 10 of these families. Of the eight respondents that remembered giving their consent, none were unhappy about their decision and none felt that their baby being in a study increased their burden of anxiety. Eight of the 10 would be unhappy if doctors were not required to seek permission to include their infant in a study.

\section{DISCUSSION}

Obtaining consent for research in children presents many

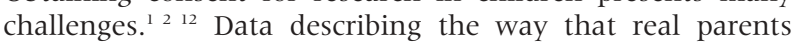
experience the process are few. The infants in our trial were randomised to different clinical management plans when critically ill. Eighteen months later, 12\% of parents could not remember giving consent and a further $6 \%$ were unsure. Even when all non-responders are included, at least $8 \%$ of parents could not remember. Our study was performed before the Griffiths report ${ }^{7}$ was published.

Snowdon $\mathrm{et}_{\mathrm{al}}^{\mathrm{8}}$ interviewed the parents of 21 infants who were enrolled in the UK ECMO trial. All 21 infants had survived. Some parents were not aware that their baby was in a trial, and only 12/21 were aware of the random nature of the treatment allocation. In the Euricon study, ${ }^{10}$ five of 200 parents could not remember giving consent. In the immediate period after their infant's admission to a neonatal unit, parents remember little of what is said to them by medical and nursing staff. ${ }^{13}{ }^{14}$ It is clear that even when written consent is obtained and the process is supported by printed information, an appreciable number of parents will not remember this later and this could lead to considerable distress or mistrust. This problem should be addressed proactively by researchers. Consent is a process that must be maintained over time. ${ }^{12}$ This may be facilitated by providing continuing contact and support, encouraging further questions, providing parental newsletters, and planning for sufficient research funding to support such initiatives. Indeed, in future research into parental views on consent, these activities may themselves improve the response rate.

Only two parents refused consent for the trial. High consent rates are obtained for trials in many neonatal units. ${ }^{15}$ However, the requirement for written consent is seen by some as a reason for poor recruitment, ${ }^{16}$ and alternatives, such as enrolment without consent ${ }^{4}$ and obtaining consent after randomisation only from those allocated to experimental treatment, have been suggested. ${ }^{3}$ Snowdon $e t$ al interviewed the parents of surviving infants enrolled into the ECMO trial, and about half found the concept of Zelen randomisation unacceptable. More parents of infants not randomised to ECMO found the concept unacceptable than did parents of infants randomised to ECMO, indicating that the Zelen approach was rejected by those who it is aimed to protect. Harth and Thong ${ }^{17}$ found that $14.5 \%$ of parents felt that obtaining consent was unnecessary as they would do what the doctors said anyway. Zupancic et $a^{18}$ found that $32 \%$ of parents would prefer their doctor to decide for them.

We found that, despite having expressed a high degree of satisfaction with their experience of neonatal research, 83\% of parents would be unhappy for us to be allowed to include their baby in a study that had ethics committee approval without having to ask their permission. If all the nonresponders were included, at least 53\% of parents would be unhappy about this. Burgess et al found that $93 \%$ of parents were against the option of letting the doctor decide. ${ }^{19}$

We sent the questionnaires 18 months after the study finished to reduce bias from loyalty. We could not use a third party because the Trust stipulated that the parents be approached by a doctor from the unit. The institutional ethics committee initially denied us permission to approach 
bereaved parents. Most studies have excluded bereaved parents. We wrote to a representative of SANDS, who discussed the study with a group of bereaved parents. They felt that bereaved parents may gain considerable comfort from knowing that their baby contributed to research that may benefit future babies and that they should not be excluded. On receipt of the responses from SANDS, the ethics committee gave us permission to approach bereaved parents. Of the 20 bereaved parents, the 10 who responded indicated a high degree of satisfaction with their children's involvement in research and no increased burden of distress. The initial well intentioned paternalism on the part of the ethics committee might have denied these parents a voice.

Most parents who responded were happy to have enrolled their infant in a study. They felt that they were given a full explanation and knew they were free to change their mind at any time. They tended not to have felt an increased burden of anxiety. The response rate of $64 \%$ means that the findings should not be overinterpreted. These experiences relate largely to a single trial in one neonatal unit. It cannot be assumed that they will apply to other studies or other units.

Some of the infants took part in several studies. This could have sensitised the parents to trials, making them more likely to remember, or inoculated them to trials, making them less stressful. More detailed information may have been obtained using a more qualitative approach if resources had been available.

By enrolling their infant in the study, $12 \%$ of our respondents thought that they may get better care. An inclusion benefit in trials is well recognised. ${ }^{20}$ Zupancic et al ${ }^{18}$ found that risk-benefit assessments, attitudes towards research, and the integrity of the consent process influence parents consenting for their newborn infants to be research subjects. Gallo et $a l^{21}$ found that people placed in a hypothetical situation became more likely to consent for a trial the worse their outlook. Levene et $a l^{22}$ found that parents were more likely to consent to a trial when their infant was critically ill soon after birth than they were a week later. It may be that our parents were anxious enough about their infants to consent to almost anything.

The trial required randomisation soon after admission which limited the time available to parents for consideration. This is common in neonatal trials. Parents who felt pressurised were significantly more likely to have been college educated. Harth and Thong ${ }^{23}$ found that tertiary education increased the likelihood of parents refusing consent. Most patients have not thought about research before their admission to hospital. ${ }^{24}$ The sense of pressure may have reflected a feeling that there was inadequate time for all of the issues to be fully addressed.

The trial made $24 \%$ of parents more anxious. Explaining the trial necessitated a detailed description of the baby's condition and introduced medical uncertainty about the optimal treatment. Concern about increasing patients' burden of anxiety can motivate clinicians to give incomplete information to patients about trials or to avoid enrolling them. ${ }^{25}$ Clinicians also acknowledge that obtaining fully informed consent places an extra emotional burden on them too. ${ }^{26}$ A noble intention to protect patients may be partly motivated by self protection.

It is debatable whether informed consent is ever obtained in its fullest sense, ${ }^{27}$ but most of our parents felt satisfied that they had been adequately informed..$^{28}$ We have not measured the quality of the information they were given but rather their satisfaction with it and the degree to which they felt that they understood it. However, the facts that about $12 \%$ of parents did not remember giving consent for their child to participate in a randomised clinical trial and 31\% understood little or none of the information provided are of major concern to all researchers. There is a clear need for further work involving patient groups looking at ways in which the process of participation in clinical trials can be improved.

\section{ACKNOWLEDGEMENTS}

We thank the members of the Stillbirth and Neonatal Death Society who gave helpful feedback on the value of including the experiences of bereaved parents in this study. The study was funded by the University of Edinburgh Development Trust.

\section{Authors' affiliations}

B J Stenson, J-C Becher, N Mclntosh, Neonatal Unit, Simpson Centre for Reproductive Health, Royal Infirmary, Little France, Edinburgh EH16 4SU, Scotland, UK

\section{REFERENCES}

1 Mason S. Obtaining informed consent for neonatal randomised controlled trials: an "elaborate ritual"? Arch Dis Child Fetal Neonatal Ed 1997:76:F143-5.

2 Anonymous. Your baby is in a trial [editorial]. Lancet 1995;345:805-6.

3 Zelen M. A new design for randomized clinical trials. N Engl J Med 1979:300:1242-5.

4 Modi N. Clinical trials and neonatal intensive care [letter]. Arch Dis Child Fetal Neonatal Ed 1994;70:F231-2.

5 Snowdon C, Elbourne D, Garcia J. Zelen randomisation: attitudes of parents participating in a neonatal clinical trial. Control Clin Trials 1999:20:149-71.

6 Smith R. Babies and consent: yet another NHS scandal [editorial]. BMJ 2000;320:1285-6.

7 NHS Executive. West Midlands Regional Office. Report of a review of the research framework in North Staffordshire Hospital NHS Trust. http:// www.doh.gov.uk/wmro/northstaffs.htm (updated 8 May 2000, accessed 1 July 2000)

8 Snowdon C, Garcia J, Elbourne D. Making sense of randomisation: responses of parents of critically ill babies to random allocation of treatment in a clinical trial. Soc Sci Med 1997;45:1337-55.

9 UK Collaborative Trial Group. UK collaborative randomised trial of neonatal extra-corporeal membrane oxygenation. Lancet 1996;348:75-82.

10 Mason SA, Allmark PJ. Obtaining informed consent to neonatal randomized controlled trials: interviews with parents and clinicians in the Euricon study. Lancet 2000;356:2045-51.

11 Stenson BJ, Glover RM, Wilkie RA, et al. Randomised controlled trial of respiratory system compliance measurements in mechanically ventilated neonates. Arch Dis Child Fetal Neonatal Ed 1998;78:F15-19.

12 Mclntosh N, Bates P, Brykczynska G, et al. Guidelines for the ethical conduct of medical research involving children. Royal College of Paediatrics, Child Health: Ethics Advisory Committee. Arch Dis Child 2000;82:177-82.

13 Redshaw ME, Harris A. Maternal perceptions of neonatal care. Acta Paediatr 1995;84:593-8.

14 Perlman NB, Freedman JL, Abramovitch R, et al. Informational needs of parents of sick neonates. Pediatrics 1991;88:512-18.

15 Campbell H, Boyd KM, Surry SAM. Journals should require routine reporting of consent rates [letter]. BMJ 1997;315:247.

16 Tobias JS. BMJ's present policy (sometimes approving research in which patients have not given fully informed consent) is wholly correct. BMJ 1997;314:1111-14.

17 Harth SC, Thong YH. Parental perceptions and attitudes about informed consent in clinical research involving children. Soc Sci Med 1995;40:1573-7.

18 Zupancic JAF, Gillie P, Streiner DL, et al. Determinants of parental authorisation for involvement of newborn infants in clinical trials. Pediatrics 1997;99:e6.

19 Burgess E, Singhal N, Amin H, et al. Consent for clinical research in the neonatal intensive care unit: a retrospective survey and a prospective study. Arch Dis Child Fetal Neonatal Ed 2003;88:F280-5.

20 Lantos JD. The "inclusion benefit" in clinical trials [editorial]. J Pediatr 1999;134:130-1.

21 Gallo C, Perrone F, De Placido S, et al. Informed versus randomised consent to clinical trials. Lancet 1995;346:1060-4.

22 Levene M, Wright I, Griffiths G. Is informed consent in neonatal randomised controlled trials ritual? [letter] Lancet 1996;347:475.

23 Harth SC, Thong YH. Sociodemographic and motivational characteristics of parents who volunteer their children for clinical research: a controlled study. BMJ 1990;300:1372-5.

24 Larson E, McGuire D. Patient experiences with research in a tertiary care setting. Nurs Res 1990;39:168-71.

25 Williams CJ, Zwitter M. Informed consent in European multicentre randomised clinical trials: are patients really informed? Eur $J$ Cancer 1994;30A:907-10.

26 Walterspiel JN. Informed consent: influence on patient selection among critically ill premature infants. Pediatrics 1990;85:119-21.

27 Silverman WA. The myth of informed consent: in daily practice and in clinical trials. J Med Ethics 1989;15:6-11.

28 Ingelfinger FJ. Informed (but uneducated) consent. N Engl J Med 1972;287:465-6. 


\section{IMAGES IN NEONATAL MEDICINE.}

Diffuse pneumocephalus caused by neonatal Enterobacter cloacae meningitis

A

5 day old full term male infant admitted with a two day history of fever, irritability, and convulsions was diagnosed as having Enterobacter cloacae septicaemia and meningitis. A computed tomography (CT) brain scan on admission showed cerebral oedema and areas of low density signals near the occipital horns of the lateral ventricles. A repeat CT scan five days after admission (fig l) revealed the presence of diffuse pneumocephalus. $\mathrm{T}_{1}$ weighted magnetic resonance images of the brain three days later (fig 2), as well as a CT scan two weeks after admission, showed a pronounced interval increase in the collection of intracranial air. The baby died from multiorgan failure 18 days after admission.

Pneumocephalus, defined as the presence of air or gas in the cranial cavity, is a known complication of head trauma, neurosurgical procedures, and cranial irradiation. It has been reported associated with meningitis caused by mixed aerobic-anaerobic infection as well as Clostridium perfringens, Streptococcus pneumoniae, and Clostridium septicum, mostly in adult patients.

To our knowledge, this is the first reported case of diffuse pneumocephalus associated with Enterobacter cloacae meningitis in a neonate. The presence of focal areas of pneumocephalus in the CT scan on admission before lumbar puncture and its subsequent interval increase in the following days exclude other causes of pneumocephalus in our patient.

M R Sedaghatian P Ramachandran N Rashid Mafraq Hospital, PB 2951, Abu Dhabi, United Arab Emirates; sreza@emirates.net.ae

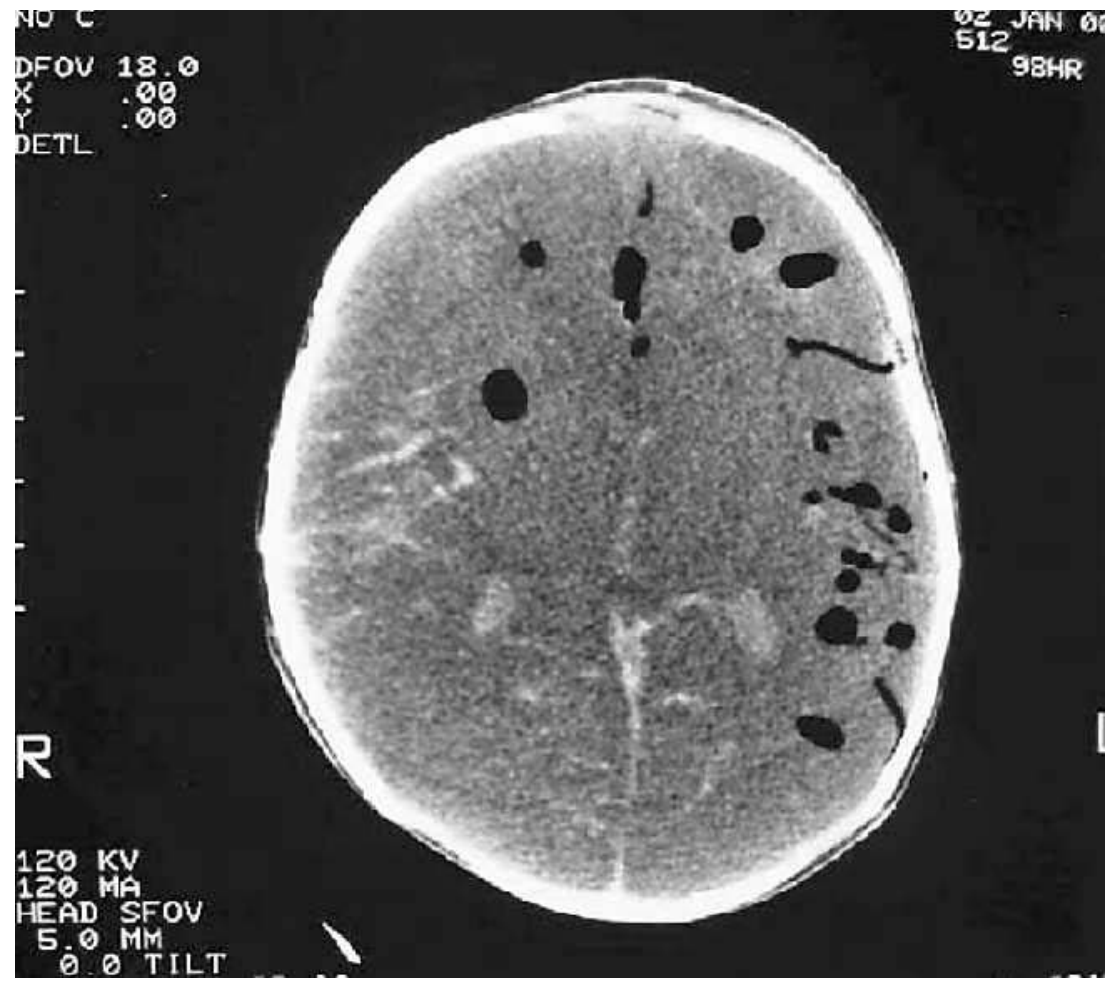

Figure 1 Computed tomography scan of the brain of a 10 day old male infant showing diffuse pneumocephalus.

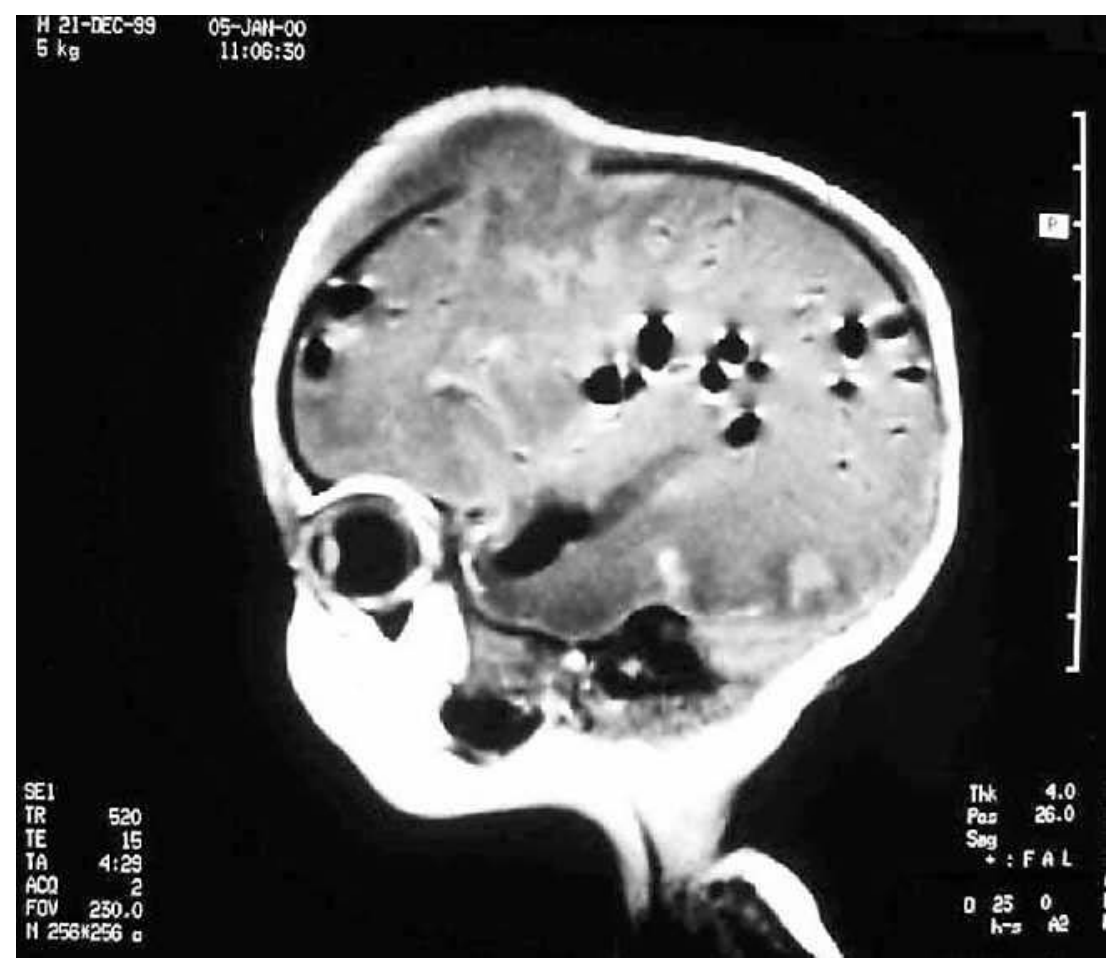

Figure 2 Magnetic resonance image of the brain three days later showing a pronounced interval increase in intracranial air. 